\title{
Acesso aos Serviços de Saúde, Condições de Saúde e Exposição aos Fatores de Risco: percepção dos pescadores ribeirinhos do Rio Machado de Ji-Paraná, RO'
}

\author{
Access to Health Services, Health Conditions and Exposure \\ to Risk Factors: perception of riparian fishermen of the \\ Machado River in Ji-Paraná, RO
}

\author{
Ivania Prosenewicz \\ Assistente Social. Mestre em Saúde Coletiva. Mestranda do Curso \\ de Ciências da Saúde do Instituto de Assistência Médica ao Servi- \\ dor Público Estadual de São Paulo (IAMSPE). Professora do Curso \\ de Serviço Social do Centro Universitário Luterano de Ji-Paraná \\ (CEULJI/ULBRA). \\ Endereço: Rua Martinho Lutero, 270, CEP 76907-474, Ji-Paraná, \\ RO, Brasil. \\ E-mail: iprosenewiczðyahoo.com.br

\section{Umberto Gazi Lippi} \\ Médico. Doutor em Medicina. Livre-Docente de Obstetrícia. \\ Orientador do Curso de Pós- Graduação do Instituto de Assistência \\ Médica ao Servidor Público Estadual de São Paulo (IAMSPE). Pro- \\ fessor Titular da Faculdade de Ciências da Saúde da Universidade \\ Metropolitana de Santos. \\ Endereço: Rua Borges Lagoa, 564, cj. 32, Vila Clementino, CEP \\ 04038-000, São Paulo, SP, Brasil. \\ E-mail: uglippi®uol.com.br \\ I Trabalho realizado em Ji-Paraná/Ro em colaboração com o Curso \\ de Pós-Graduação em Ciências da Saúde do Instituto de Assistência \\ Médica ao Servidor Público Estadual - SP.
}

\section{Resumo}

Este artigo apresenta um estudo sobre as percepções dos pescadores ribeirinhos de Ji-Paraná/RO quanto ao acesso aos serviços de saúde da rede pública local. Objetiva também identificar as percepções das condições de saúde e a exposição aos fatores de risco dessa população. Trata-se de uma pesquisa qualitativa e analítico-descritiva. Para a coleta de dados, utilizaram-se entrevistas semiestruturadas e observação livre, realizadas em visitas domiciliares no período de setembro a novembro de 2009 , com 23 pescadores, sendo 15 homens e 8 mulheres. A população pesquisada percebe estar exposta a diversos riscos e problemas de saúde, com maior frequência no período das enchentes. No trabalho, há risco de acidentes, afogamentos e outros perigos devido à inexistência ou precariedade quanto ao uso de Equipamentos de Proteção Individual - EPI. A maioria (19) dos entrevistados relatou problemas de saúde, como dores na coluna, nas pernas, musculares, cãibras, problemas de visão, dor de cabeça, gripe e doenças de pele. Os pescadores ribeirinhos participantes da pesquisa identificam muitas dificuldades no acesso aos serviços de saúde da rede pública e a deficiência no saneamento básico. Além disso, a área pesquisada não é de abrangência da estratégia Saúde da Família. Assim, faz-se necessária a formulação de políticas que viabilizem a melhoria da infraestrutura, a redução das desigualdades no atendimento à saúde e a ampliação da estratégia Saúde da Família.

Palavras-chave: Acesso; Saúde; Pescadores. 


\section{Abstract}

This paper presents a study about the perceptions of riparian fishermen in the city of Ji-Paraná, Northern Brazil, in relation to their access to the health services of the local public network. In addition, it aims to identify this population's perceptions concerning health conditions and their exposure to risk factors. It is a qualitative, analytical-descriptive research. For data collection, semi-structured interviews and free observation were conducted in home visits in the period of September, October and November 2009, with 23 fishermen ( 15 men and 8 women). The interviewed population notices they are exposed to several risks and health problems, mainly in the flood period. In their work, there are risks of accidents, drowning and others hazards, due to lack or insufficiency in relation to the use of Individual Protection Equipments - IPE. The majority of the interviewees (19) reported health problems, like back pain, pain in the legs, muscular pain, cramps, sight problems, headaches, flu and skin diseases. The riparian fishermen who participated in the research identify many difficulties in their access to the public health services and deficiencies in basic sanitation. Besides, the researched area is not covered by the Family Health Strategy. Thus, it is necessary to formulate policies that enable the improvement in infrastructure, the reduction in health care inequalities and the expansion of the Family Health Strategy.

Keywords: Access; Health; Fishermen.

\section{Introdução}

A região amazônica do país é muito rica e repleta de recursos naturais. No entanto, com toda essa riqueza, boa parte da população enfrenta o desemprego e a violência que cresce a cada dia, revelando, assim, o lado sombrio das desigualdades e da injustiça social que atinge a população da região Norte do Brasil.

Segundo Diniz e colaboradores (2007), a população dos estados que compõem a Amazônia mantém níveis de pobreza muito elevados e baixa qualidade de vida, se comparados com a média nacional. Existe um crescimento econômico proveniente da exploração de recursos naturais em meio a uma pobreza crônica.

Rondônia, parte da Amazônia, ganhou condição de estado em 1981, formada por uma das mais diversificadas populações do Brasil, oriundas de todas as regiões do país. 0 estado possui uma população, segundo estimativa do IBGE (2009), de 1.503.928 habitantes distribuídos em 52 municípios. Conforme o mapa de pobreza e desigualdade dos municípios brasileiros, realizado pelo IBGE e relativo a 2003 (IBGE, 2003), Rondônia apresenta incidência da pobreza de $27,02 \%$ da população. Já o município de Ji-Paraná, o segundo maior do estado, tem uma população estimada de 111 .010 mil habitantes, e a incidência da pobreza é de $31,74 \%$ da população (IBGE, 2009).

Em relação ao sistema local de serviços de saúde na rede pública, Ji-Paraná/RO possui 28 estabelecimentos públicos de saúde, os quais atendem os usuários do Sistema Único de Saúde, sendo um o Hospital Municipal que possui um pronto socorro geral de atendimento exclusivo pelo SUS (Brasil, s.d.).

Quanto ao aspecto geográfico, a cidade de JiParaná desenvolveu-se nas duas margens do Rio Machado, denominando-se atualmente como $1^{\circ} \mathrm{e}$ $2^{\circ}$ Distritos, um na margem esquerda e o outro na margem direita do rio, sendo esses distritos ligados por uma ponte que cruza toda a frota da BR-364.

Na cidade de Ji-Paraná, além do crescimento habitacional de forma desordenada nas margens do Rio Machado, existe o agravante quanto à elevação do nível das águas no período das chuvas, que ocorre todos os anos, e, posteriormente, os riscos diversos de contaminação trazidos pelas águas.

Entretanto, boa parte dessa população ribeirinha 
atingida pelas enchentes tem como principal fonte de renda a pesca. Esses pescadores com características peculiares - diferentes das demais regiões da Amazônia - não vivem em áreas rurais e/ou em colônias agrupadas. Os pescadores citados estão inseridos no espaço da cidade, são cadastrados em uma Colônia de Pescadores, mas residem em ruas e bairros diferentes. Alguns até próximos, como no caso das ruas selecionadas para a amostra da pesquisa, mas têm como vizinhos moradores com outras fontes de renda (emprego no comércio, domésticas, pedreiros etc.). Assim, o que diferencia o ribeirinho pescador dos demais é o seu trabalho, pois a atividade da pesca expõe a pessoa a diversos riscos e doenças, levando-as, consequentemente, a precisar utilizar mais vezes os serviços de saúde.

Boa parte das casas dos ribeirinhos da cidade de Ji-Paraná não é adaptada para que as pessoas vivam às margens do rio, conforme relatos e descrições de moradias apresentados nos resultados e na discussão. Consequentemente, para os ribeirinhos pescadores, o problema não está somente no período das enchentes, mas no cotidiano do trabalho, porque necessitam passar dias no rio sem voltar para casa e acabam ficando expostos a vários riscos.

Esse é um fator atribuído à pressão econômica a que os pescadores artesanais profissionais estão sujeitos, motivados principalmente pelos baixos rendimentos devido à ação de atravessadores que impõem preços baixos ao pescado. Assim, os pescadores têm aumentado cada vez mais a jornada de trabalho, tanto no que diz respeito ao tempo de trabalho quanto à distância percorrida para alcançar os cardumes (Neto e col., 2005).

No entanto, a Lei Orgânica da Saúde n. 8.08o aponta como fatores determinantes e condicionantes da saúde "a alimentação, a moradia, o saneamento básico, o meio ambiente, o trabalho, a educação, o transporte, o lazer, o acesso aos bens e serviços essenciais", entre outros (Brasil, 1990). Partindo dessa premissa, observa-se que as infraestruturas sociais, econômicas e de saneamento básico são condições que influenciam de forma significativa a saúde das pessoas.

A partir dessa problemática, esta pesquisa apresenta as percepções dos pescadores ribeirinhos do Rio Machado quanto ao acesso aos serviços de saúde da rede pública, considerando a perspectiva da Constituição Federal de 1988, que em seu artigo 196 assinala:

A saúde éum direito de todos e um dever do Estado, garantido mediante políticas sociais e econômicas que visem à redução do risco de doenças e de outros agravos e ao acesso universal igualitário às açõese serviços para sua promoção, proteção e recuperação (Brasil, 1988).

O estudo visa também identificar as percepções dos pescadores quanto às condições de saúde e à exposição aos fatores de risco.

\section{Metodologia}

A abordagem deste estudo é de natureza qualitativa e analítico-descritiva. Optou-se pela pesquisa qualitativa por permitir a interação entre o pesquisador e os sujeitos da pesquisa e por trabalhar com um universo de significados, motivações, aspirações, crenças, valores e atitudes, o que corresponde a um espaço mais profundo das relações (Minayo, 1994).

Realizou-se inicialmente um estudo exploratório que, segundo Piovesan e Temporini (1995), é parte integrante da pesquisa principal e tem por objetivo conhecer a variável de estudo tal como se apresenta, seu significado e o contexto no qual ela se insere.

Assim, durante o período de enchente do Rio Machado, foram feitas visitas às residências alagadas com a assistente social do Programa de Atenção Integral à Família - PAIF e com a cooperação do Corpo de Bombeiros - uma vez que só era possível chegar a essas casas de barco. Identificaram-se nessas visitas vários ribeirinhos pescadores, o que permitiu definir como seria selecionada a população do presente estudo.

Posteriormente, buscaram-se dados na Colônia de Pescadores Z9 de Ji-Paraná para verificar o número de pescadores associados a essa colônia e quantos residiam na beira do Rio Machado no perímetro urbano. Dessa forma, foram listados 156 pescadores associados a essa Colônia, sendo 40 ribeirinhos do Rio Machado residentes do perímetro urbano da cidade, considerando o $1^{\circ}$ e o $2^{\circ}$ distrito.

Desses 40 pescadores realizou-se uma amostra por área para a coleta de dados que, conforme Barros e Lehfeld (199o, p. 6o), "é o tipo de amostra muito 
utilizada em pesquisa de comunidade [...]". A partir disso, foram selecionadas duas ruas - uma no $1^{\circ}$ e a outra no $2^{\circ}$ Distrito - pela proximidade das residências dos pescadores, por residirem mulheres pescadoras e por serem frequentemente alagadas pelas enchentes. Nesse ponto, excluíram-se aqueles que na segunda visita não foram encontrados em casa.
Assim, de um universo de 40 pescadores cadastrados na Colônia Z9 e residentes nas margens do Rio Machado no perímetro urbano (Figura 1) da cidade de Ji-Paraná, foi selecionada uma amostra de 23 pescadores, que corresponde a 57,5\% do total, sendo 15 homens e 8 mulheres.

\section{Figura I - Mapa da Cidade de Ji-Paraná/RO}

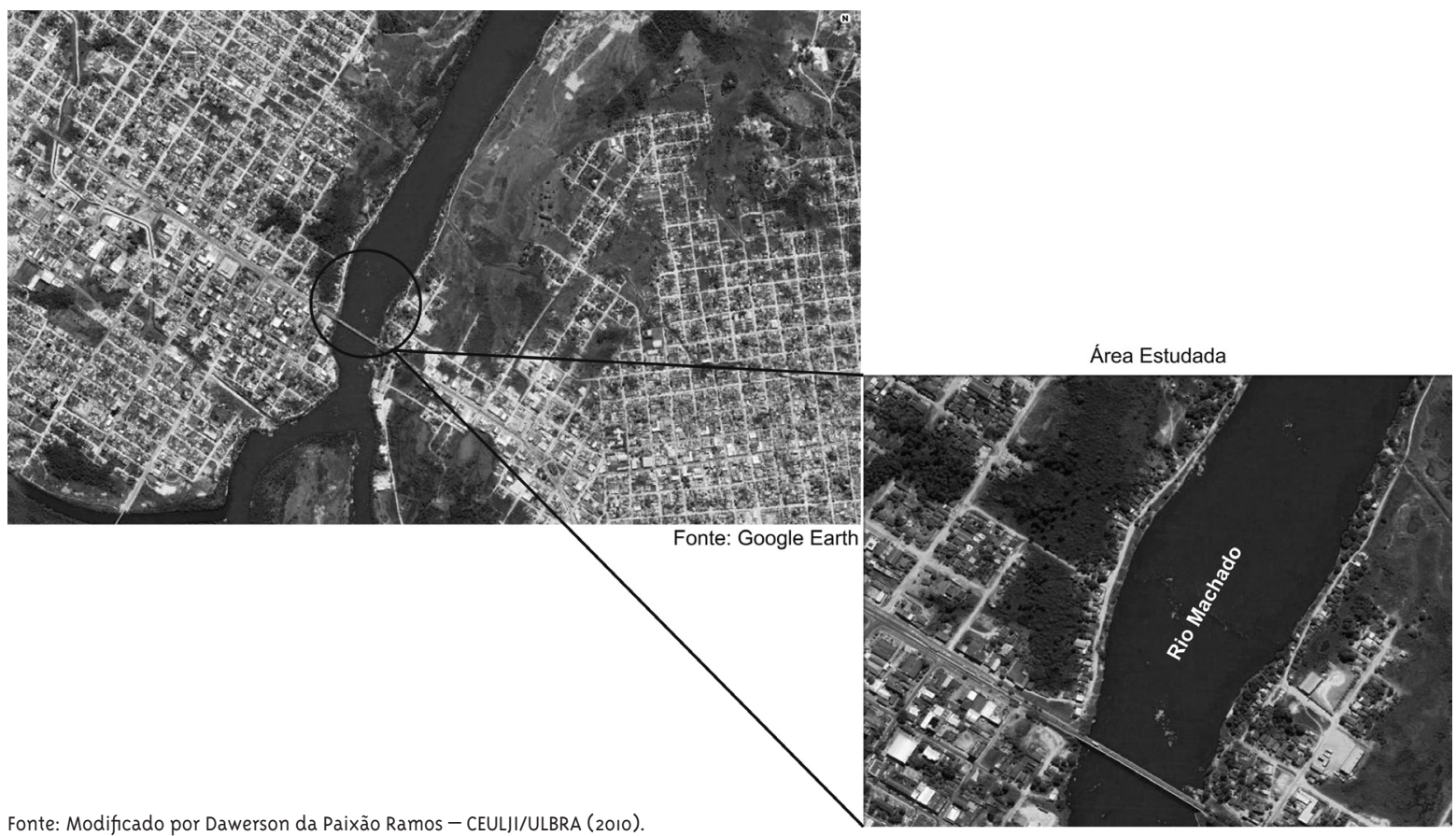

A coleta de dados ocorreu por meio de observação livre e de entrevistas semiestruturadas que combinam perguntas fechadas e abertas, "onde o entrevistado tem a possibilidade de discorrer sobre o tema, sem respostas ou condições prefixadas pelo pesquisador" (Minayo, 1994, p. 108). Essas entrevistas foram realizadas durante visitas domiciliares nos meses de setembro, outubro e novembro de 2009, tendo como questões norteadoras: Quais as dificuldades e facilidades encontradas no acesso aos serviços de saúde da rede pública de Ji-Paraná?; Quais os fatores de risco encontrados pelo pescador no trabalho?; Quais os principais problemas de saúde enfrentados pelo pescador?; Quais os fatores de risco e as doenças mais frequentes durante as enchentes?; Sua casa já foi alagada durante o período das enchentes? Se sim, que providência tomaram?.
Para verificar as condições de habitação, saneamento básico e nível de escolaridade, optou-se por questões fechadas.

A análise dos dados foi realizada através do processo de classificação e categorização, examinadas e agrupadas a partir das características comuns (Barros e Lehfeld, 1990).

Como se trata de uma pesquisa envolvendo seres humanos, o projeto foi submetido à aprovação do Comitê de Ética em Pesquisa do Centro Universitário Luterano de Ji-Paraná (CEULJI/ULBRA). De acordo com a resolução do Conselho Nacional de Saúde (CNS) 196/96, cada entrevistado assinou um termo de Consentimento Livre e Esclarecido. Assim, para a preservação da identidade dos sujeitos participantes da pesquisa, utilizaram-se codinomes como entrevistado 1 , entrevistado 2 etc. 


\section{Resultados e Discussão}

\section{Acesso aos serviços de saúde na rede pública: um olhar dos pescadores ribeirinhos}

No Brasil, o Movimento da Reforma Sanitária, que se iniciou no final da década de 1970 e culminou com a VIII Conferência Nacional de Saúde em 1986, foi o marco histórico da luta pela saúde como um direito do cidadão e dever do Estado e a universalidade do acesso aos serviços de promoção e recuperação.

Segundo Bravo e Matos (2006), o relatório dessa Conferência foi transformado em recomendações que serviram de base para a negociação dos defensores da Reforma Sanitária na reformulação da Constituição Federal. Porém, a política de saúde proposta nesse projeto foi questionada e, na segunda metade da década de 1990, tornou-se articulada ao mercado privatista. O Estado passou a garantir um mínimo aos que não podem pagar para o setor privado, com atenção focalizada para as populações vulneráveis.

Assis e colaboradores (2003) salientam que esse sistema é excludente por ser regulado pela lógica do mercado e condicionar o direito à assistência universal aos mecanismos de racionamento dos gastos. Como consequência, ocorreu a precarização da qualidade da atenção prestada nos serviços públicos, excluindo os grupos sociais com maior poder de organização. É um sistema segmentado e desarticulado da cadeia organizativa do sistema como um todo.

No entanto, há a seguinte controvérsia: a saúde assegurada na Constituição Federal de 1988 como um "direito de todos e dever do Estado" passa a ser seletiva, pois o atendimento aos cidadãos que não podem esperar na fila é realizado pelo setor privado. Porém, há que se questionar sobre a "universalidade" do acesso à saúde.

Nesse contexto, buscou-se conceituar a palavra acesso na utilização dos serviços de saúde. Travassos e Martins (2004, p. 196-197), após analisarem diferentes autores, constataram que "prevalece a ideia de que acesso é uma dimensão do desempenho dos sistemas de saúde associado à oferta”. Quanto ao uso dos serviços, estes dependem de fatores predisponentes das necessidades de saúde e de fatores contextuais.

Para Pires e colaboradores (2010), há iniquidades no acesso e ineficiência no sistema de saúde quanto aos usuários do SUS. Isso está associado à desarticulação entre a oferta dos serviços e as demandas trazidas pela população, amparada na dificuldade dos profissionais em escutar as necessidades de saúde da população. "A concepção de oferta se insere na produção de ações de saúde no âmbito da política pública, por meio da articulação contextual entre rede física e uso adequado de equipamentos, profissionais e tecnologias para atender às demandas da população" (p. 1010).

Questionados sobre as facilidades e dificuldades encontradas no acesso aos serviços de saúde da rede pública de Ji-Paraná, a maioria (16) relatou várias dificuldades. Uma pequena parcela dos entrevistados (5) demonstrou algumas facilidades e duas pessoas não utilizam os serviços da rede pública. O Quadro 1 apresenta uma síntese e a frequência das respostas.

\section{Quadro I - Síntese e frequência das principais dificuldades e facilidades de acesso aos serviços de saúde da rede pública de Ji-Paraná/RO relatadas pelos pescadores}

\begin{tabular}{|l|l|c|}
\hline \multirow{5}{*}{ Avaliação dos serviços } & Citações dos ribeirinhos & Frequência \\
\hline \multirow{5}{*}{ Dificuldades } & Demora no atendimento & 8 \\
\cline { 2 - 3 } & Demora em conseguir exames específicos & 7 \\
\cline { 2 - 3 } & Falta de médicos especialistas e demora a marcar consulta & \multicolumn{1}{|c|}{5} \\
\cline { 2 - 3 } Facilidades & Falta de remédios nas UBS & 31 \\
\cline { 2 - 3 } & Total & 2 \\
\hline & Serviços estão melhorando & 2 \\
\cline { 2 - 3 } & Bom atendimento & 3 \\
\cline { 2 - 3 } & Atendimento no plantão do Hospital Municipal & 7 \\
\cline { 2 - 3 } & Total & \\
\hline
\end{tabular}

Fonte: Elaborado a partir das respostas das entrevistas, Ji-Paraná, 2009.

Obs.: Vários entrevistados citam mais de uma dificuldade ou facilidade, por isso o número da frequência é maior que o de entrevistados. 
As principais queixas dos entrevistados são a falta de médicos especialistas e a demora em marcar consultas. Cumpre salientar, de acordo com dados do Ministério da Saúde (Brasil, s.d.), que há 148 médicos (clínicos gerais e especialistas) que atendem pelo SUS no Município de Ji-Paraná/RO, tendo uma população, citada anteriormente, estimada de 111.010 mil habitantes, o que corresponde a aproximadamente 1,3 profissionais para cada 1.ooo habitantes. A proporção estaria dentro da preconizada pela Organização Mundial de Saúde (OMS), que é de um médico por mil habitantes. Entretanto, Ji-Paraná é um município polo regional de saúde, atendendo assim vários outros municípios da região, o que aumenta a demanda por atendimentos.

Na questão de saúde preventiva, duas mulheres entrevistadas relataram que não fazem exames preventivos, as demais realizam todos os anos.

As dificuldades encontradas estão exemplificadas nas falas dos usuários reproduzidas adiante:

[...] comecei a sentir dores nas costas muito fortes; aí descobri que eram pedras na vesícula, mas o doutor descobriu que tenho problemas de coração, aí não pode me operar. Pediu vários exames, mas só marcaram pra dezembro, isso foi em setembro, assim juntei meu dinheirinho e fiz os exames [...], os remédios não tinha no postinho, também tive que comprar, sorte que "nois tinha" pescado bastante peixe naquela semana, aí pude ir na farmácia e comprar e como faz o pobre que não tem dinheiro e nem crédito na farmácia? [...] (Entrevistado $n^{\circ}{ }^{5}$ )

[...] meu filho teve problemas de adenoide, realizou o tratamento fora do município, consegui encaminhamento pelo SUS, mas gastei muito em passagem e em hotel, os remédios, alguns peguei no postinho e outros comprei porque não tinha [...] (Entrevistado $n^{\circ} 6$ )

[...] teve uma vez, logo no início do ano, que fiquei muito mal, doía muito minhas costa, aífui no hospital municipal e tomei uma injeção pra dor, o médico disse que eu tinha que procurar um especialista, mas não fui, sei das dificuldades de conseguir consulta com especialista e demora muito, fiquei bom e voltei a pescar, não posso perder tempo, minha família depende do meu pescado. (Entrevistado $\left.\mathrm{n}^{\circ} 22\right)$
[...] já melhorou bastante, anos atrás era muito pior, mas ainda falta remédio nos postinhos e alguns exames demoram muito. (Entrevistado ${ }^{\circ}{ }^{\circ}$ 12)

Observa-se que os pescadores identificam facilidade no atendimento médico do plantão do Hospital Municipal, mas, quanto aos especialistas, exames específicos e medicações requisitadas por meio do Sistema Único de Saúde - SUS - há grande dificuldade e demora.

Na questão dos serviços de saúde de alta complexidade, como problemas de coração, conforme a fala do entrevistado número 5, estes são encaminhados para a capital, Porto Velho.

As dificuldades no acesso aos serviços de saúde relatadas pelos pescadores acarretam em prejuízos na renda da família. Como citado anteriormente, o pescador precisa ficar dias no rio sem voltar para casa, devido à desvalorização de seu pescado e à diminuição de peixes no rio, onde cada vez é necessário ir mais longe. No entanto, para a maioria dos entrevistados a pesca é a única fonte de recursos financeiros. Assim, a demora por atendimento faz com que ele perca o dia de trabalho - muitas vezes vários dias - e, quando não consegue, conforme relato do entrevistado número 22, espera melhorar e volta ao trabalho sem o diagnóstico do problema, ficando um longo período distante das unidades de saúde.

Nesse contexto, Kassouf (2005) destaca que os sistemas de saúde de forma geral possuem diversos problemas e um grande número desses problemas não está relacionado somente a fatores biológicos ou médicos, mas a problemas econômicos e administrativos. A autora salienta também que problemas de saúde ocasionam grandes perdas econômicas para a sociedade devido à falta ao trabalho e à queda na produtividade.

Percebe-se, assim, que o Estado ainda não está conseguindo proporcionar aos usuários dos serviços de saúde o acesso universal e igualitário, acarretando em prejuízos socioeconômicos aos usuários. Dessa forma, há contradição entre aquilo que é previsto no SUS e o que realmente acontece no cotidiano dos usuários dos serviços, em que o direito à saúde tem sido negligenciado.

Para Ribeiro e colaboradores (2005), a política da saúde sofre consequências das estratégias de ajuste econômico, nas quais há lentidão na concretização 
do SUS, o que resulta na ineficácia de um sistema de referência e contrarreferência, acarretando dificuldades de acesso às consultas e exames, na qualidade de alguns serviços e nos atendimentos de profissionais especializados.

Nessa linha de raciocínio, Oliveira e colaboradores (2009), em um estudo realizado em Juiz de Fora/MG, atribuíram as dificuldades de acesso aos serviços de saúde nas Unidades Básicas de Saúde às restrições quanto ao número de vagas para consultas; ao horário de funcionamento; à indefinição dos critérios de urgência; ao agendamento de consultas inadequadas segundo a realidade do usuário; à demora na obtenção do atendimento; às filas de madrugada e também à desorganização do sistema "referência - contrarreferência", além do aspecto geográfico.

Esses problemas também são apontados pelos entrevistados com a peculiaridade do município pesquisado. Nesse cenário, pode-se evidenciar que o acesso à saúde pública tem sido um desafio para a sociedade brasileira, a qual vem enfrentando limitações em relação ao atendimento público de determinados serviços ou programas.

Quanto ao aspecto geográfico, em uma pesquisa realizada por Oliveira (2009) no Serviço de Atenção à AIDS em Salvador, constatou-se que a distância geográfica dos serviços de saúde é um dos fatores a ser considerado quando o tema é acesso à assistência. Nesse mesmo estudo, as entrevistadas queixaram-se da distância da residência aos serviços, agravada por um sistema de transporte público urbano precário.

Essa realidade é encontrada em Ji-Paraná, onde as Unidades Básicas de Saúde ficam distantes das famílias pesquisadas e o sistema de transporte público é insuficiente, há poucos ônibus circulando pela cidade e nas ruas onde foi realizada a pesquisa os ônibus não transitam, dificultando ainda mais o acesso.

Na avaliação dos serviços de saúde, identificou-se também que as pescadoras sentem a falta de Agentes Comunitários, pois possuem muitas dúvidas em relação a sua saúde. Uma das mulheres entrevistadas tem o diagnóstico de diabetes e toma medicação obtida na Unidade Básica de Saúde. No entanto, não recebe orientações para realizar mudanças de rotina na vida diária, fato que está trazendo agravos ao seu problema.

Observa-se que, no nível de atenção primária, as ações de promoção e prevenção à saúde não estão contemplando essa população, nenhum dos entrevistados recebe visita de Agentes Comunitários de Saúde, identificando que a área pesquisada não é de abrangência da estratégia Saúde da Família.

A esse respeito, Besen e colaboradores (2007) mencionam que a estratégia Saúde da Família tem como papel principal a prática educativa, voltada para a promoção da saúde, abrangendo um conjunto de atividades com a finalidade de melhorar as condições de bem-estar e acesso aos bens e aos serviços sociais.

Segundo indicadores da Atenção Básica do Ministério da Saúde (Brasil, s.d.) com base no ano de 2009, a abrangência da estratégia Saúde da Família no Município de Ji-Paraná/RO é de $27,4 \%$ da população. Quanto ao número de equipes, há 13 equipes de Saúde da Família, sendo que o ideal seria 46 equipes, ou seja, há um déficit de 33 equipes.

Em relação ao saneamento básico, a área pesquisada não possui rede de esgoto. Assim, questionou-se sobre o escoamento do esgoto doméstico e identificou-se que 17 dos entrevistados utilizam fossa rudimentar, quatro têm o esgoto despejado no rio e dois não responderam.

Por outro lado, $67,8 \%$ da população do município utilizam água de poço ou nascente; 30,8\% recebem água da rede geral e 1,4\% outra forma de abastecimento de água (Brasil, s.d.).

Quanto ao abastecimento da água na área pesquisada, dos 23 entrevistados, 10 utilizam água de poço, os demais utilizam água da rede geral fornecida pela Companhia de Água e Esgoto de Rondônia - CAERD.

Silva e colaboradores (2009, p. 110) salientam que a cidade de Ji-Paraná/RO não possui sistema público de coleta e tratamento de esgoto; dessa forma, as águas residuárias produzidas pela população são lançadas em sistemas rústicos ou fossas. No entanto, muitos habitantes da cidade utilizam água subterrânea extraída de poços denominados "amazonas" ou tubulares rasos, o que pode ser considerado de grande vulnerabilidade ambiental, por se tratar de um sistema urbano raso, poroso e permeável. Além disso, há uma grande quantidade de fossas domésti- 
cas instaladas na região. Nas análises sobre a potabilidade das águas de poço realizadas em um bairro da cidade, identificaram-se elevadas concentrações de nitrato, o que indica que "a utilização de águas subterrâneas da zona urbana merece a atenção das autoridades locais, principalmente pelos reflexos na saúde da população".

O Ministério da Saúde (Brasil, 20oga) alerta que o sistema de abastecimento público de água é fundamental para garantir saúde à população. Esse sistema abrange um conjunto de obras, instalações e serviços que envolvem captação, adução, tratamento, reservação e distribuição da água destinada às comunidades.

Para Razzolini e Günther (2008), as condições locais de saneamento podem contribuir para a qualidade da água de consumo. Nos lugares onde não existe ou é precário o esgotamento sanitário, verifica-se "disposição de resíduos sólidos a céu aberto, fator que induz a proliferação de insetos e roedores vetores, também contaminantes podem ser disseminados e alcançar as fontes de água e os reservatórios de armazenamento" (p. 28). Nesse caso, a população exposta pode adquirir doenças infecciosas relacionadas com excretas, lixo e vetores, como é o caso dos pescadores e pescadoras participantes deste estudo.

Em relação à participação de mulheres na atividade pesqueira, Freitas e Batista (1999), em um estudo realizado com populações ribeirinhas da Amazônia, identificaram que apesar de a pesca ser uma atividade eminentemente masculina, em todas as comunidades estudadas por eles a pesca é desenvolvida com ativa participação de mulheres.

Quanto à mulher pescadora participante desse estudo, ficou evidente que, além de todos os problemas enfrentados pelos pescadores homens, elas mantêm dupla jornada de trabalho, realizam os afazeres domésticos e se preocupam com os filhos que deixam sozinhos no período em que ficam pescando, conforme relatos:

A mulher é muito mais valiosa que o homem, consegue acompanhar no trabalho e ainda volta pra casa e limpa tudo, faz comida, cuida de filhos [...] (Entrevistada ${ }^{\circ}{ }^{19}$ )

Mal durmo de noite quando estou acampada, fico muito preocupada com meus filhos que ficam sozi- nhos em casa, já são grandes, mas sempre precisam da mãe, também tenho medo de cobra e onça, uma vez escutei barulho da onça no mato, corremos para o barco e descemos pro rio [...] (Entrevistada $n^{\circ} 2$ )

Nesse contexto, concorda-se com Gama (2006) ao assinalar que a avaliação em saúde, quando aborda as relações de gênero, deve voltar-se para captar mudanças nas condições de saúde das mulheres, nos aspectos inerentes ao seu lugar social de subordinação, para assim superar a concepção de avaliação como simples medida de desvio entre o esperado e o realizado no campo das políticas de saúde. Entretanto, é preciso um olhar mais atento para as políticas de saúde voltadas à mulher, pois estas apresentam peculiaridades em relação aos homens.

Outro fator observado nesta pesquisa foi o desconhecimento que os pescadores têm quanto ao direito à saúde, ou seja, se há muita demora ou não recebem o atendimento pelo SUS, desistem ou buscam os serviços no setor privado. Nenhum dos entrevistados relatou que procurou o Ministério Público para validar seus direitos. Um dos fatores que pode estar contribuindo para essas desinformações é o baixo nível de escolaridade dos pescadores entrevistados. A maioria (16) não concluiu o ensino fundamental, outros (6) são analfabetos e somente um (1) pescador relatou que completou o ensino médio. Também acredita-se que a falta de comunicação seria outro fator, pois eles ficam muito tempo isolados no rio e dificilmente participam de reuniões de conselhos ou conferências de saúde.

Assim, buscou-se verificar as condições de saúde, bem como a exposição a fatores de risco dos pescadores ribeirinhos pelas suas próprias percepções.

\section{Percepção sobre as condições de saúde e exposi- ção aos fatores de risco}

Definir condições de saúde não é tão simples, pois o próprio conceito de saúde segundo Scliar (2007) reflete a conjuntura social, econômica, política e cultural. Saúde não representa a mesma coisa para todas as pessoas. Dependerá da época, do lugar, da classe social e de valores individuais.

Por outro lado, pode-se conceituar fatores de risco como a exposição supostamente associada com o desenvolvimento de uma doença, podendo ser genéticos ou ambientais (Brasil, 2009a). 
Com relação à percepção saúde dos pescadores, constatou-se que eles identificam vários problemas e se veem expostos a riscos físicos, biológicos e ergonômicos, conforme os seguintes discursos:

[...] sinto muita dor nas costas, não sei se rins ou coluna, tem dias que não posso trabalhar aí espero ficar bom e vou pro rio novamente [...], acho que pode ser pelo peso que precisa erguer, e também fico muito tempo sentado no barco (Entrevistado $\mathrm{n}^{\circ}{ }^{11}$ ).

[...] tenho dores nas pernas, na coluna, cãibras e visão ruim, por causa da posição que fico no barco, $e$ as vistas acho que é a claridade do sol que bate muito forte na água [...], até uso óculos, mas são os comprados nos camelôs, não deve esta ajudando (Entrevistado ${ }^{\circ}{ }^{8}$ ).

Fui no postinho, olha o que saiu nas minhas pernas, não sei o que é [...] o médico mandou procurar um dermatologista, estou esperando a consulta [...], deve ser da água do rio, ou algum bicho me picou (Entrevistado $\mathrm{n}^{\circ}$ 21).

Observa-se que a maioria (19) dos pescadores apresenta algum tipo de queixa; entre elas, as mais citadas foram: dores na coluna, nas pernas, musculares, cãibras - que podem ser consequência do excessivo trabalho braçal -, problemas de visão, dor de cabeça, gripe e doenças de pele, conforme exposto no Quadro 2.

Rosa e Mattos (2010) chegaram à conclusão, em uma pesquisa realizada com pescadores e catadores de caranguejo da Baía de Guanabara, de que essa atividade apresenta agravos à saúde, decorrentes dos vários fatores de risco e agentes patológicos a que estão expostos, pelas condições de vida e trabalho e pela falta de proteção social. Há riscos de acidentes com embarcações, afogamentos, acidentes com o próprio pescado, variações climáticas, exposição à radiação solar, ruídos dos motores dos barcos, excesso de peso, agravados pela extensa jornada de trabalho e pouco uso de Equipamentos de Proteção Individual - EPI.

Através dos depoimentos a seguir e com as observações realizadas, evidencia-se que há semelhanças nos resultados encontrados por Rosa e Mattos (2010) com a presente pesquisa:

\section{Quadro 2 - Relação e frequência dos problemas de saúde mais citados}

\begin{tabular}{|l|c|}
\hline Principais queixas & Frequência \\
\hline Dores na coluna & 8 \\
\hline Dores nas pernas & 5 \\
\hline Dores musculares & 3 \\
\hline Cãibras & 3 \\
\hline Problemas de visão & 4 \\
\hline Dor de cabeça & 3 \\
\hline Cripe & 3 \\
\hline Doenças de pele & 3 \\
\hline Total & 32 \\
\hline
\end{tabular}

Fonte: Elaborado a partir das respostas das entrevistas, Ji-Paraná, 2009. Obs.: As queixas repetem-se nas entrevistas.

Não uso colete, e poucos pescadores usam [...] medo até tenho, pois já morreu um casal há uns dois ou três anos, o barco virou e caíram na cachoeira (Entrevistado $\mathrm{n}^{\circ} 11$ ).

o peso da caixa de gelo émuito, aísofro pra colocar no barco, ele fica tão pesado que a água chega perto de entrar [...], não uso colete e nem luvas, difícil passar uma semana sem cortar as mãos com linhas ou mesmo com peixe (Entrevistado $\mathrm{n}^{\circ} 16$ ).

Outra semelhança encontrada foi em relação à pesquisa realizada por Neto e colaboradores (2005) no Estado de Tocantins, em que identificaram que dos 92 pescadores profissionais artesanais que participaram do estudo, 56 sofreram no mínimo um acidente de trabalho nos últimos seis meses, antes e durante o estudo. A proporção de incidência de acidentes do trabalho obtida para a população estudada foi de $85,9 \%$ ao ano.

Em relação às mulheres entrevistadas, somente uma relatou que usa o colete salva-vidas. Uma delas relatou que não sabe nadar, mas, mesmo assim, não utiliza o colete. Evidenciou-se que a maioria dos sujeitos do presente estudo não faz o uso de EPI, tais como coletes salva-vidas, luvas etc., que poderiam evitar ou reduzir os acidentes.

No entanto, está previsto no campo de atuação do Sistema Único de Saúde - SUS, no Art. $6^{\circ}$, a execução de ações de saúde do trabalhador (Brasil, 1990), o que 
não está ocorrendo com a população pesquisada.

Outro fator de risco observado ocorre no período das chuvas, pois a elevação do nível do Rio Machado alaga as ruas e residências das famílias ribeirinhas. Além dos danos materiais, há lixo pelas ruas, invadindo as casas. A população fica exposta às doenças que podem ocorrer nessas situações, como leptospirose, dengue, entre outras. Também há risco de picadas de animais peçonhentos trazidos pelas águas.

De acordo com o Plano de Contingência de Vigilância em Saúde Frente às Inundações, as enchentes figuram entre os desastres de origem natural que mais provocam danos à saúde pública e ao patrimônio, com elevada morbimortalidade, em decorrência do efeito direto das enchentes e das doenças infecciosas secundárias, e também provoca transtornos nos sistemas de água e saneamento (Brasil, 2009b).

Nesse sentido, buscou-se verificar as características das moradias dos participantes desta pesquisa, constatando-se que 7 dos entrevistados residem em casas de madeira; 8 em casas de madeira e material aproveitado; 3 em casas mistas, de alvenaria e madeira; 4 em casas de alvenaria, mas sem acabamento; 1 em casa de alvenaria com acabamento.

Em relação à propriedade, dos 23 entrevistados a maioria possui casa própria (16), 4 residem em casas alugadas e 3 habitam em casas cedidas.

Observou-se que boa parte das casas não é adaptada para morar às margens do rio (Figura 2), assim são alagadas facilmente no período das enchentes. Mesmo nas moradias mais altas, houve relatos de pessoas que precisaram sair com a elevação das águas, por medo das constantes invasões de animais peçonhentos.

Dos sujeitos pesquisados, a maioria (15) teve suas casas alagadas nos últimos cinco anos, alguns (3) relataram que a água não chegou a casa, mas alagou toda a rua; outros (5) responderam que não tiveram problemas com o alagamento. Em caso positivo de alagamento, foram questionados sobre: Que providência tomou nessa situação?. Alguns responderam que foram para um abrigo providenciado pela Prefeitura Municipal, outros para casas de parentes ou amigos, e muitos ergueram os móveis e permaneceram na casa por medo de roubo. A maioria

\section{Figura 2 - Características das moradias dos ribeirinhos da Cidade de Ji-Paraná/RO}

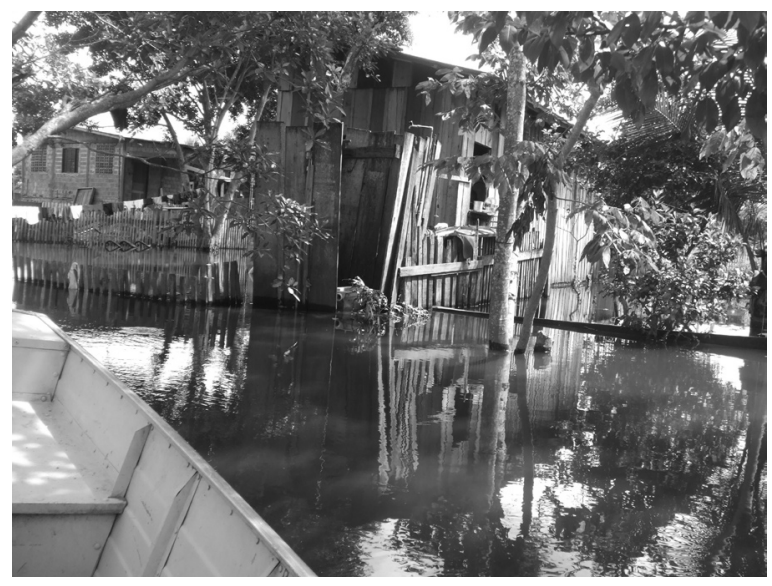

Créditos: Ivania (fev./2009).

(9) dos que enfrentaram esse problema mudou-se posteriormente para uma casa mais alta ou fez aterro e ergueu a mesma casa, os demais permaneceram na mesma residência.

Boa parte dos entrevistados relatou alguma situação de risco ou agravo à saúde durante o período de enchente. Entre os relatos, destacam-se as seguintes falas:

[...] meu filho ficou com coceira em todo o corpo vários dias, eu dizia pra não entrar na água, mas vivia nadando naquela água suja, depois passou, não sei o que era nem levei no postinho (Entrevistada $\left.\mathrm{n}^{\circ} 3\right)$.

O filho de um vizinho que vive brincando com meus meninos pisou em uma arraia na porta de casa, levou uma ferroada e ficou dias sofrendo, também a água é muito suja não dá pra vê no que pisa (Entrevistado $\mathrm{n}^{0} 23$ ).

Eu e todos daqui de casa tivemo diarreia quando a água chegou dentro de casa, passamo um sufoco, não é fácil cozinhar com as coisas tudo erguida e água em toda a casa, a higiene fica difícil [...] quase nem dormimo de noite de medo que entra cobra [...] (Entrevistado $\mathrm{n}^{0} 18$ ).

Conforme o Ministério da Saúde (Brasil, 2009b), as doenças provocadas pelas enchentes não se apresentam imediatamente, mas geralmente a partir 
das 48 horas seguintes. Assim, é possível aparecer doenças relacionadas com a falta ou o mau manejo de água potável, problemas relacionados com a pele, infecções respiratórias e doenças transmitidas por vetores. Em certos casos, verifica-se o aumento de casos por mordeduras de serpentes.

Observou-se, neste estudo, que para o pescador ser ribeirinho facilita muito o seu trabalho, pois o barco chega perto da casa, não necessitando de transporte para pôr na água, conforme os seguintes relatos:

Moro aqui há mais de 10 anos, para mim me mudar daqui fica muito difícil, o lucro do pescador é muito pouco, compra gelo, tem o combustivel do barco e ainda se depender de carro para pôr o barco na água, vamo te que pagar pra trabaiá (Entrevistado $\left.\mathrm{n}^{0} 9\right)$.

Minha família toda vive da pesca, eu já nem estou mais indo, mais meu filho e minha nora vão e ficam mais de uma semana rio abaixo, a casa deles alaga sempre, mas como vão sair de lá? Não dá, sempre moramo perto do rio énossa vida, éfácil,é sóresolve e pega o barco, coloca todas as nossas tralhas e sai pra pesca (Entrevistado $\mathrm{n}^{\circ} \mathrm{1}$ ).

De acordo com as falas anteriores, percebe-se que, para o pescador, morar na beira do rio, sujeito às inundações e a todos os riscos à saúde trazidos pelas águas, principalmente no perímetro urbano, como é o caso dos sujeitos participantes desse estudo, não é uma questão de escolha, mas muitas vezes de necessidade, devido à facilidade de colocar o barco na água e os equipamentos necessários para a pesca.

\section{Considerações Finais}

Pode-se afirmar, com base nas percepções dos pescadores ribeirinhos entrevistados, que os serviços de saúde pública no município pesquisado apresentam problemas que precisam ser superados. Há ineficiência em vários tipos de atenção. Isso deixa claro que há inúmeros obstáculos de acesso que precisam melhorar para que se chegue à universalidade, integralidade e equidade propostas pelo SUS.

Há necessidade de ampliação da atenção à saúde, com melhorias no saneamento básico e expansão da estratégia Saúde da Família, a qual inclui promoção, prevenção, recuperação, reabilitação de doenças e agravos mais frequentes, possibilitando a participação social, conforme diretrizes do Ministério da Saúde, pois conforme Garbois e colaboradores (2008) um dos desafios da estratégia Saúde da Família é superar as iniquidades que se estendem ao longo da história. Outro desafio é operacionalizá-la dentro de um território nacional heterogêneo dos pontos de vista geopolítico, econômico, cultural e social.

No caso da mulher pescadora, é necessário promover práticas educativas em saúde, integrá-las em grupos de convivência e assim possibilitar a troca de saberes e o acesso a informações.

É preciso que se intensifiquem os estudos sobre morbimortalidade dos pescadores profissionais artesanais, principalmente os que residem na Amazônia, visto que há dificuldades para encontrar dados específicos dessa população, bem como pesquisas que indiquem as condições de saúde e de acesso aos serviços de saúde de outras colônias de pescadores. Somente assim será possível comparar os estudos e buscar melhorias no que diz respeito à saúde dos pescadores da Amazônia e, dessa forma, também respeitar sua cultura e seu modo de viver.

Por fim, é de suma importância a elaboração de políticas específicas intersetoriais para a população que vive da pesca, em função da exposição a diversos riscos, considerando a dimensão sociocultural do processo saúde-doença.

\section{Referências}

ASSIS, M. M. A.; VILLA, T. C. S.; NASCIMENTO, M. A. A. Acesso aos serviços de saúde: uma possibilidade a ser construída na prática. Ciência \& Saúde Coletiva, Rio de Janeiro, v. 8, n. 3, p. 815$823,2003$.

BARROS, A. J. P. de; LEHFELD, N. A. S. Projeto de pesquisa: propostas metodológicas. Petrópolis: Vozes, 1990.

BESEN, C. B. et al. Estratégia saúde da família como objeto de educação em saúde. Saúde e Sociedade, São Paulo, v. 16, n. 1, p. 57-68, 2007.

BRASIL. Constituição (1988). Constituição da República Federativa do Brasil. Brasília, DF: Senado, 1988. 
BRASIL. Lei n 8.08o, de 19 de setembro de 1990. Dispõem sobre as condições para a promoção, proteção e recuperação da saúde, a organização e o funcionamento dos serviços correspondentes e dá outras providências. Diário Oficial da União, Brasília, DF, 20 set. 1990. p. 18055.

BRASIL. Ministério da Saúde. O SUS de A a Z: garantindo saúde nos municípios. Conselho Nacional das Secretarias Municipais de Saúde. 3. ed. Brasília, DF, 20oga.

BRASIL. Ministério da Saúde. Secretaria de Vigilância em Saúde. Comitê das Enchentes. Emergência de saúde pública de importância nacional - ESPIN. Enchentes na região Norte e Nordeste do Brasil - 20ogb. Disponível em: http:// portal.saude.gov.br/portal/arquivos/pdf/informe enchentes_norte_nordeste_2009.pdf. Acesso em: 20 dez. 2009.

BRASIL. Ministério da Saúde. Cadastramento Nacional de Estabelecimentos de Saúde. Brasília, s.d. Disponível em: http://cnes.datasus.gov.br/ Mod_Ind_Unidade.asp?VEstado=11\&VMun=110012\& VUni= Acesso em: 04 abr. 2010.

BRAVO, M. I.; MATOS, M. C. de. Reforma sanitária e projeto ético-político do serviço social: elementos para o debate. In: BRAVO, M. I. S. et al (Orgs.). Saúde e serviço social. São Paulo/Rio de Janeiro: Cortez/UERJ, 20o6. p. 25-47.

DINIZ, M. B. et al. A Amazônia (Legal) brasileira: evidências de uma condição de armadilha da pobreza? In: ENCONTRO NACIONAL DE ECONOMIA, 35., 2007, Recife. Anais... Recife: ANPEC, 2007. Disponível em: <http://www.anpec. org.br/encontro2007/artigos/Ao7Aogo.pdf >. Acesso em: 14 ago. 2009.

FREITAS, C. E.; BATISTA, V. S. A pesca e as populações ribeirinhas da Amazônia central. Revista Brasileira de Ecologia, São Paulo, v. 3, n. 1, 1999. Disponível em: <http://ecologia.ib.usp. br/seb-ecologia/revista/n199/pesca\%2o.html>. Acesso em: 06 set. 2010.
GAMA, A. S. de. Gênero e avaliação da qualidade da atenção em serviços de saúde reprodutiva. In: BRAVO, M. I. S. et al. (orgs.). Saúde e serviço social. São Paulo: Cortez; Rio de Janeiro: UERJ, 2006. p. 79-96.

GARBOIS, J. A.; VARGAS, L. A.; CUNHA, F. T. S. O direito à saúde na Estratégia Saúde da Família: uma reflexão necessária. Physis: Revista de Saúde Coletiva, Rio de Janeiro, v. 18, n. 1, p. 27- 44, 2008.

IBGE - Instituto Brasileiro de Geografia e Estatística. Estimativa das populações residentes 20o9. Disponível em: http://www.ibge.gov.br/ home/estatistica/populacao/estimativa2009/ POP2009_DOU.pdf. Acesso em: 02 set. 2010.

IBGE - Instituto Brasileiro de Geografia e Estatística. Mapa de pobreza e desigualdade - municípios brasileiros 2003. Disponível em: http://www.ibge.gov.br/estadosat/temas.php?sigl $\mathrm{a}=$ ro\&tema=mapapobrezazoo3. Acesso em: 02 set. 2010.

KASSOUF, A. L. Acesso aos serviços de saúde nas áreas urbana e rural do Brasil. Revista de Sociologia e Economia Rural, Brasília, v. 43, n. 1, p. 29-44, 2005. Disponível em: http://www.scielo. $\mathrm{br} / \mathrm{pdf} / \mathrm{resr} / \mathrm{v} 43 \mathrm{n} 1 / 25834 . \mathrm{pdf}$. Acesso em: 10 mar. 2010.

MINAYO, M. C. de S. O desafio do conhecimento: pesquisa qualitativa em saúde. São Paulo/Rio de Janeiro: Hucitec/Abrasco, 1994.

NETO, D. G.; CORDEIRO, R. C.; HADDAD JR, V. Acidentes do trabalho em pescadores artesanais da região do Médio Rio Araguaia. Tocantins, Brasil. Cadernos de Saúde Pública, Rio de Janeiro, v. 21, n. 3, p.795-803, 2005.

OLIVEIRA, I. B. N. Acesso universal? Obstáculos ao acesso, continuidade do uso e gênero em um serviço especializado em HIV/AIDS em Salvador, Bahia, Brasil. Cadernos de Saúde Pública, Rio de Janeiro, v. 25, n. 2, p. S259-S268, 2009. 
OLIVEIRA, L. H.; MATTOS, R. A.; SOUZA, A. I. S. Cidadãos peregrinos: os "usuários" do SUS e os significados de sua demanda a prontos-socorros e hospitais no contexto de um processo de reorientação do modelo assistencial. Ciência \& Saúde Coletiva, Rio de Janeiro, v. 14, n. 5, p. 19291938, 2009.

PIOVESAN, A.; TEMPORINI, E. R. Pesquisa exploratória: procedimento metodológico para o estudo de fatores humanos no campo de saúde pública. Revista Saúde Pública, São Paulo, v. 29, n. 4, p. 318-25, 1995.

PIRES, M. R. G. M. et al. Oferta e demanda por média complexidade/SUS: relação com atenção básica. Ciência \& Saúde Coletiva, Rio de Janeiro, v.15, n. 1, p. 1009-1019, 2010.

RAZZOLINI, M. T. P.; GÜNTHER, W. M. R. Impactos na saúde das deficiências de acesso à água. Saúde e Sociedade, São Paulo, v.17, n.1, p. 21-32, 2008.

RIBEIRO, S. P. et al. O cotidiano profissional do assistente social no Programa Saúde da Família em Campina Grande. Revista Katálysis, Florianópolis, v. 8, n. 2, p. 248-255, 2005.
ROSA, M. F.M.; MATTOS, U.A.O. A saúde e os riscos dos pescadores e catadores de caranguejo da Baía de Guanabara. Ciência e Saúde Coletiva, Rio de Janeiro, v.15 (Supl. 1), p. 1543-1552, 2010. Disponível em: http://www.scielo.br/scielo.php?script=sci arttext\&pid=S1413-81232010000700066. Acesso em: 03 mar. 2011.

SCLIAR, M. História do conceito de saúde. Physis: Revista de Saúde Coletiva, Rio de Janeiro, v. 17, n. 1, p. 29-41, 2007.

SILVA, A. C. et al. Impacto físico-químico da deposição de esgotos em fossas sobre as águas de aquífero freático em Ji-Paraná-RO. REA: Revista de Estudos Ambientais, Blumenau, v. 11, n. 2, p. 101112, 2009. Disponível em: http://proxy.furb.br/ojs/ index.php/rea/article/view/1569/1202. Acesso em: o4 mar. 2010.

TRAVASSOS, C.; MARTINS, M. Uma revisão sobre os conceitos de acesso e utilização de serviços de saúde. Cadernos de Saúde Pública, Rio de Janeiro, v. 20, n. 2, p. S19o-S198, 2004.

Recebido em: 14/04/2010

Reformulado em: 09/03/2011

Aprovado em: 01/07/2011 